\title{
RESPONSIVE REDESIGN AND ITS EFFECTS ON PerCeived UsefulNess
}

\author{
Kimberly Fischer and Damian Schofield \\ Department of Computer Science, State University of New York, Oswego, NY
}

\begin{abstract}
This paper describes the introduction of a new website at TCGplayer, who provide an online store for Magic the Gathering collectible cards. This paper describes an experiment that was undertaken to test a new, responsive design, against the current, non-responsive design. It was predicted that redesigning the shopping cart for a mobile device screen, will result in a higher Perceived Usability (PU), and higher satisfaction, as indexed using the Technology Acceptance Model (TAM).
\end{abstract}

\section{KEYWORDS}

Collectible Card Game, Responsive Design, Technology Acceptance Model, HCI, Usability

\section{INTRODUCTION}

Magic: The Gathering (MTG) was created by the Wizards of the Coast in $1993[1,2]$. It is thought to be the first Collectible Card Game (CCG) and it has created a large subculture of devoted players. In MTG, players compete with each other using their own decks of cards which they purchase within Local Gaming Stores (LGS), trade with one another, or buy through the secondary market $[3,4]$.

MTG, played by over twenty million people worldwide, has grown into a large scale, contemporary social activity, which has created a new revenue source for the gaming entertainment industry $[1,2,4]$. Illustrating just how lucrative the CCG market is, the Pokemon franchise, which does include a CCG, is the highest-grossing media entertainment franchise today. Pokemon generates more money than Star Wars or Harry Potter [5]. Further, Hasbro, the parent company for MTG, claimed that it ended its fourth year of $25 \%$ revenue growth since 2015 and since 2014 has brought in an estimated annual revenue of \$250 million [1].

\section{INTRODUCTION}

Magic: The Gathering (MTG) was created by the Wizards of the Coast in 1993 [1, 2]. It is thought to be the first Collectible Card Game (CCG) and it has created a large subculture of devoted players (Thomas, M. et al, 2019; Limbert, 2012). In MTG, players compete with each other using their own decks of cards which they purchase within Local Gaming Stores (LGS), trade among one another or buy through the secondary market (Thomas, M., Shyjka, A., Gjomemo, R., 2019).

\subsection{Secondary Markets}

The secondary market is valuable for reselling specialty, rare, or collectible items. The CCG market is twofold: First, there is the primary market, which is comprised of the initial sales of 
new CCGs; and the secondary market, which consists of players buying, selling, and trading used CCGs $[4,5]$. Research shows that MTG currently holds roughly $57.2 \%$ of the volume of secondary card sales [6].

According to recent studies, one-third of shoppers begin browsing for trading cards from a secondary marketplace [7]. In 2018, secondary online marketplace sales accounted for 52\% of worldwide e-commerce sales, or $\$ 1.66$ trillion [8]. Examples of secondary retailers are eBay, Amazon, and Etsy, which continue to grow rapidly in popularity and profitability. For example, Etsy has reported to now have close to 1.6 million active sellers, and 26.1 million active buyers [9]. EBay's total e-commerce sales in the US are expected to reach $\$ 35.89$ billion, which works out to be approximately $6.1 \%$ of all US e-commerce sales [10]. The CCG world also has several well-known secondary market giant stores to shop from. Setting the market value for cards and collectibles are Channel Fireball, Star City Games, and TCGplayer.

TCGplayer, a secondary market retailer for MTG, offers a digital marketplace for buying and selling gaming memorabilia. On average, they provide over four million pages of pricing data each day via their website [11]. The estimated annual revenue for TCGplayer in 2019 was $\$ 60.6$ million [12].

Currently, several of their web pages are unresponsive and therefore present multiple friction points for users. The risk for TCGplayer is that their unresponsive web pages could decrease the Perceived Usability (PU) of a site which, in turn, could negatively impact the shopping behavior of the customer.

\subsection{Responsive Design}

Four billion people are anticipated to be using internet retail by 2020 [13]. For any CCG industry to continue to be prosperous, understanding and predicting shopper's behaviors, and how they access these secondary marketplaces, will be crucial. By creating positive user experiences across all device screen sizes, revenue gains from returning shoppers within the secondary market can be bolstered $[14,15,16]$.

Pointing to the essence of responsive design, research shows that most shoppers prefer accessing e-commerce and m-commerce sites using their mobile phones [17]. It has also been shown that consumer loyalty is higher for $\mathrm{m}$-commerce sites that are responsive, aesthetically designed, and built from the user's perspective $[14,16]$.

M-commerce can be thought of as an extension of e-commerce with the former having its own requirements for interface design [18]. For example, on a desktop screen, the overview is high, due to the larger screen size which affords full context, creating a sense of direction and Ease of use (EOU). In contrast, the smaller mobile screen limits overview of the m-commerce ecosystem, which impacts Perceived Ease of Use (PEOU). Shoppers in a modern online retail market expect all the websites they use to be responsive and enjoyable to interact with.

\subsection{Technology Acceptance Model}

In addition to considering responsive design and its effects on usage, it is also important to appreciate the mental model of the user $[19,20]$. Studies have found that when compared to users who had no previous exposure to a shopping application, experienced users took longer to browse for items after an interface update was applied [21]. Other research suggests that a user's mental model directly affects their intention to use a smartphone application [20]. This implies that the 
longer a user has become accustomed to an interface or system, the greater the friction when that interface changes. Further, the user friction could increase exponentially the further the design moved away from the initial design. Therefore, it becomes important to consider the amount of time a user has interacted with the system under consideration and other similar systems outside of that ecosystem. When implementing any future augmentations, it is important to consider how the user may react, in order to reduce user friction.

The Technology Acceptance Model (TAM), introduced in 1986, is one of the most adopted models for predicting behavior toward acceptance, or adoption, of hardware or software systems $[13,22,23,24]$. TAM essentially predicts intention to use and amount of use of a technology [25]. The TAM primarily relies on two variables; namely, Perceived Ease of Use (PEOU) and Perceived Usefulness (PU) which are influenced by the system's attributes (external variables) and the behavioral intention (Figure 1) [26, 27]. This multifaceted relationship guides researchers toward predicting actual system usage.



Figure 1. The Technology Acceptance Model [28].

Previous research utilized the TAM to evaluate the likelihood of adoption of an m-commerce site [29]. They found that a user's PEOU is indicative of its PU which directly affects behavior and actual usage. In other similar studies, the user interface design of the website was found to be influential and important toward the acceptance of technology [3, 31]. Tractinsky (1997) pioneered a particular form of design research by revealing data that links aesthetics, or the beauty of a website, with high PEOU [32]. Further TAM studies found it was important that ecommerce sites be attractive to users and that navigation be clear because it provides the users with a sense of confidence [13].

Koufaris (2001) demonstrated how emotional and cognitive experiences influenced a shopper's return to an e-commerce store and for having unplanned purchases [25]. These results were supported by prior TAM research showing that PU was a more important predictor of intended system usage than PEOU [22, 24, 33]. In other words, PU, which emerges out of responsive design, can affect consumer's willingness to adopt a site, perform a purchase, and return to the site again.

\section{EXPERIMENT}

Several of TCGplayer's web pages were previously unresponsive and therefore presented multiple friction points for potential users. In order to increase PU, and for the purpose of this research, specific attention was focussed on TCGplayer's most critical commerce page, their unresponsive shopping cart. 
Computer Applications: An International Journal (CAIJ), Vol.8, No.1, February 2021

Within TCGplayer's checkout process, shoppers are directed towards the shopping cart where they have the following interaction options: view items, edit, save for later, return to shopping or delete items. Since this page is currently unresponsive, this forces users on mobile devices to pinch and zoom to interact with their items.

This experiment aims to test the new, responsive design, against the current, non-responsive design. The prediction is that redesigning the shopping cart for a mobile screen, will result in a higher PU, and higher satisfaction, as indexed using the TAM.

Since research demonstrates that increased adoption could lead to an increase in consumer spending, unplanned spending, and consumer loyalty, the literature surrounding responsive redesign and its effects on PU needs to be researched further and expanded upon. Understanding just how impactful responsive design is on shoppers' behavior, specifically as it relates to $\mathrm{m}$ commerce sites and the potential to influence PEOU and PU, is important [34].

\subsection{Design}

The experiment conducted was a between-subjects design. Participants were randomly assigned to one of the following conditions: non-responsive (Group A) or responsive (Group B). All participants attended the lab once and after each condition completed an 11 question Technology Acceptance Model (TAM) survey to measure PEOU, PU, and Output Quality (OUT).

\subsection{Participants}

Twenty-five individuals were recruited from TCGplayer's employee population. The participants were divided into 2 groups consisting of 13 participants in group A and 12 participants in group B. There were 10 females and 15 males. Participants did not receive any type of compensation.

\subsection{Materials}

A standard Samsung smartphone was used to access TCGplayer's website in both conditions. The TAM survey provided a way to measure what a participant is seeing as helpful when it comes to accepting a system or technology. When filling out this survey, participants were asked questions which indicated the degree to which they believe that using TCGplayer's shopping cart web page will be free of effort (PEOU); the degree to which they believe that using TCGplayer's shopping cart web page would enhance his or her shopping performance (PU); and finally, the degree to which they believe that the TCGplayer shopping cart helped them perform their task well (OUT).

The TAM can be used to measure many different systems, and at different temporal scales. However, for the purposes of this study, participants were asked to rank how they felt at the moment. A shortened version of the standard TAM questionnaire was used, containing 11 questions that were the most salient to this research.

\subsection{Procedure}

Upon arrival at the lab, participants were seated at a table and presented with the informed consent form. Having signed the consent form, participants were presented with the smartphone and briefly explained the procedure. Participants in Group A (non-responsive) were asked to complete the task of editing the quantity of an item in the shopping cart from 1 to 4 , followed by tapping the "Checkout" button. After this task, they spent approximately 10 minutes filling out 
the TAM survey questions. The second condition, Group B, (responsive) completed the same task followed by the same TAM survey questions. The total experiment lasted no longer than 20 minutes per participant.

\section{RESUlts}

To test the hypothesis that guided the current study, descriptive and inferential statistical tests were conducted using data from the three categories of TAM questions: PEOU, PU, and OUT.

Table 1 presents a summary of descriptive statistics for each of the dependent variables within each group and each category of question.

Table 1. Summary of Descriptive Statistics

\begin{tabular}{ccc}
\hline & Group A & Group B \\
\cline { 2 - 3 } PEOU & & $\boldsymbol{M}(\boldsymbol{S} \boldsymbol{D})$ \\
Q1 & $4.85(1.95)$ & $5.17(1.60)$ \\
Q2 & $5.00(2.20)$ & $4.50(1.62)$ \\
Q3 & $4.85(2.15)$ & $4.74(1.71)$ \\
Q4 & $4.85(2.00)$ & $5.16(1.64)$ \\
& & \\
PU & & \\
Q1 & $4.38(2.14)$ & $4.45(1.31)$ \\
Q2 & $4.08(2.33)$ & $3.83(1.70)$ \\
Q3 & $4.00(2.31)$ & $4.80(1.64)$ \\
Q4 & $4.70(2.06)$ & $4.70(1.60)$ \\
& & \\
OUT & & \\
Q1 & $4.80(2.35)$ & $4.50(1.53)$ \\
Q2 & $5.10(1.71)$ & $4.42(1.51)$ \\
Q3 & $4.51(2.30)$ & $4.17(1.75)$ \\
& & \\
\hline
\end{tabular}

\subsection{Perceived Ease of Use (PEOU)}

The first metric of PEOU was to determine the degree to which a person using the checkout experience would be free of effort.

Within Group A (non-responsive), most respondents indicated a high PEOU with the majority of responses being a [6] or [7]. Out of 13 participants, 23\% said they found the TCGplayer shopping cart clear and understandable [PEOU 1], 38\% indicated it was easy to use [PEOU 3]. Further, $31 \%$ indicated that the shopping cart experience did not require a lot of their mental effort [PEOU 2].

The POEU results for Group A are given in Table 2 and illustrated graphically in Figure 2. Within Group B (responsive), respondents indicated a slight mix of PEOU response. Out of 12 respondents, 25\% rated the cart's clarity at a [4] [PEOU 1], while 33\% rated it a [7]. However, there was a clear division for [PEOU 2] where $25 \%$ indicated a [4] for the shopping cart experience not requiring a lot of their mental effort, while only $8 \%$ indicated a [7]. In general, 
Computer Applications: An International Journal (CAIJ), Vol.8, No.1, February 2021

[PEOU 2] responses trend toward lower ratings, with a higher percentage indicating that the responsive cart experience required a lot of their mental effort.

The POEU results for Group B are given in Table 3 and illustrated graphically in Figure 3.

Table 2. (Group A) Overview of results for perceived ease of use factor

\begin{tabular}{|c|c|c|c|c|}
\hline \multirow{3}{*}{$\begin{array}{c}\text { Strongly Disagree } \\
2\end{array}$} & $\begin{array}{c}\text { PEOU } 1 \\
(\%)\end{array}$ & $\begin{array}{c}\text { PEOU } 2 \\
(\%)\end{array}$ & $\begin{array}{c}\text { PEOU } 3 \\
(\%)\end{array}$ & $\begin{array}{c}\text { PEOU } 4 \\
(\%)\end{array}$ \\
\hline & 0 & 8 & 8 & 0 \\
\hline & 23 & 15 & 15 & 9 \\
\hline 3 & 8 & 8 & 8 & 15 \\
\hline 4 & 0 & 0 & 8 & 8 \\
\hline 5 & 23 & 8 & 0 & 15 \\
\hline 6 & 23 & 31 & 31 & 23 \\
\hline Strongly Agree & 23 & 31 & 31 & 31 \\
\hline
\end{tabular}

Table 3. (Group B) Overview of results for perceived ease of use factor

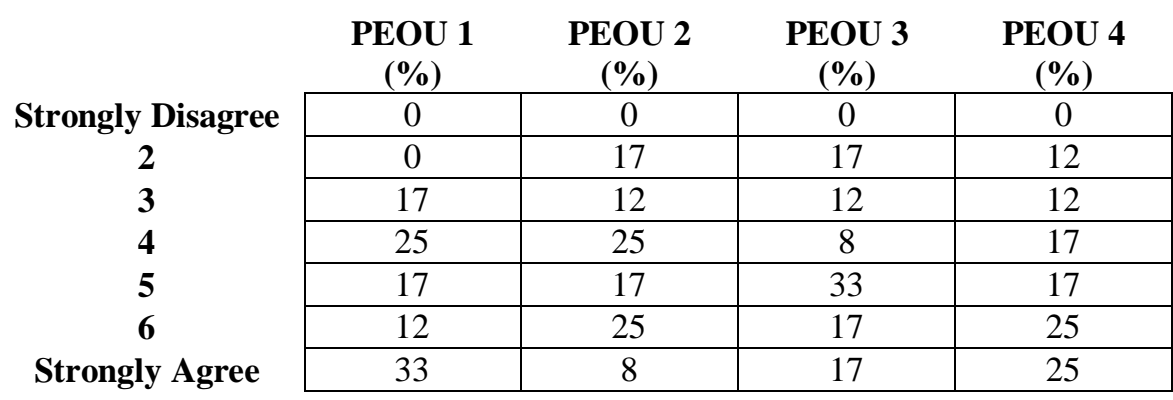

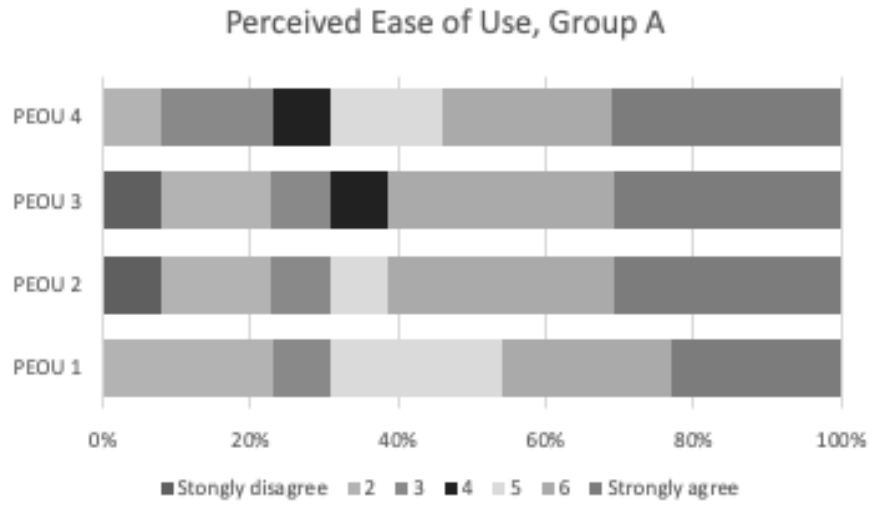

Figure 2. (Group A) Overview of results for perceived ease of use factor 
Computer Applications: An International Journal (CAIJ), Vol.8, No.1, February 2021



Figure 3. (Group B) Overview of results for perceived ease of use factor

\subsection{Perceived Usefulness (PU)}

The next series of questions set out to measure Perceived Usefulness (PU). These questions were designed to determine the degree to which a person using the checkout experience would enhance their performance. Within Group A (non-responsive), 31\% chose [5] for [PU 4] indicating that they found the TCGplayer cart to be useful. Further, the highest rating [7], was chosen $25 \%$ of the time, across all PU questions.

The PU results for Group A are given in Table 4 and illustrated graphically in Figure 4.

Within Group B (responsive), [PU 2] had 33\% indicating a low score of [2] when deciding if the responsive TCGplayer cart increased their productivity. Overall, $25 \%-33 \%$ of the group graded the shopping cart at a [4] across all questions.

The PU results for Group B are given in Table 5 and illustrated graphically in Figure 5.

Table 4. (Group A) Overview of results for perceived usability factor

\begin{tabular}{c|c|c|c|c|}
\multicolumn{1}{c}{} & \multicolumn{1}{c}{ PU 1 (\%) } & PU 2 (\%) & PU 3 (\%) & PU 4 (\%) \\
\cline { 2 - 5 } Strongly Disagree & 8 & 23 & 15 & 8 \\
\cline { 2 - 5 } $\mathbf{2}$ & 23 & 8 & 23 & 15 \\
$\mathbf{3}$ & 0 & 8 & 8 & 8 \\
$\mathbf{4}$ & 23 & 15 & 8 & 0 \\
$\mathbf{5}$ & 8 & 15 & 15 & 31 \\
\cline { 2 - 5 } $\mathbf{6}$ & 15 & 8 & 8 & 15 \\
\cline { 2 - 5 } Strongly Agree & 23 & 23 & 23 & 23 \\
\cline { 2 - 5 } & & &
\end{tabular}

Table 5. (Group B) Overview of results for perceived usability factor

\begin{tabular}{|c|c|c|c|c|}
\hline \multirow{3}{*}{$\begin{array}{c}\text { Strongly Disagree } \\
2\end{array}$} & PU $1(\%)$ & PU $2(\%)$ & PU $3(\%)$ & PU $4(\%)$ \\
\hline & 0 & 0 & 0 & 0 \\
\hline & 8 & 33 & 17 & 8 \\
\hline 3 & 17 & 8 & 0 & 17 \\
\hline 4 & 25 & 25 & 33 & 25 \\
\hline 5 & 25 & 17 & 17 & 8 \\
\hline 6 & 25 & 8 & 25 & 33 \\
\hline Strongly Agree & 0 & 8 & 8 & 8 \\
\hline
\end{tabular}


Computer Applications: An International Journal (CAIJ), Vol.8, No.1, February 2021



Figure 4. (Group A) Overview of results for perceived usability factor

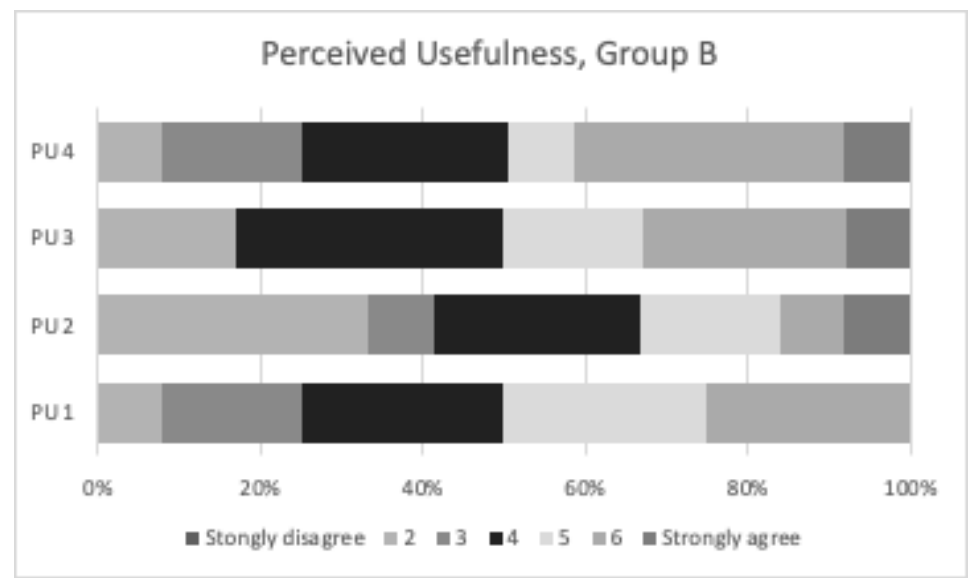

Figure 5. (Group B) Overview of results for perceived usability factor

Within Group B (responsive), [PU 2] had 33\% indicating a low score of [2] when deciding if the responsive TCGplayer cart increased their productivity. Overall, $25 \%-33 \%$ of the group graded the shopping cart at a [4] across all questions.

The PU results for Group B are given in Table 5 and illustrated graphically in Figure 5.

\subsection{Output Quality (OUT)}

The final questions regarding Output Quality (OUT) were measuring the degree to which a person believes that using the checkout experience assists them in getting the job done- finishing the checkout process. Within Group A (non-responsive), 46\% of respondents rated [OUT 2] at a [6], indicating they had no problem with the output of the TCGplayer shopping cart. Also, 38\% of participants rated [OUT 1] at a [6], indicating that the quality of the responsive cart design was perceived to be high.

The OUT results for Group A are given in Table 6 and illustrated graphically in Figure 6.

Group B (responsive) rated [OUT 1] at a 6 which accounted for $42 \%$. The next lowest score was $25 \%$ for a rating across [OUT 2,3]. Evenly, respondents indicated a moderate satisfaction with the results and quality of the cart's output. 
Computer Applications: An International Journal (CAIJ), Vol.8, No.1, February 2021

The OUT results for Group B are given in Table 7 and illustrated graphically in Figure 7.

The hypothesis predicted that the responsive shopping cart (Group B) would be rated higher than the non-responsive shopping cart (Group A) across all TAM survey questions.

Table 6. (Group A) Overview of results for output quality factor

\begin{tabular}{c|c|c|c|}
\multicolumn{1}{c}{} & \multicolumn{1}{c}{ OUT 1 (\%) } & OUT 2 (\%) & OUT 3 $(\boldsymbol{\%})$ \\
\cline { 2 - 4 } Strongly Disagree & 23 & 0 & 15 \\
\cline { 2 - 4 } $\mathbf{2}$ & 0 & 15 & 15 \\
$\mathbf{3}$ & 0 & 0 & 0 \\
$\mathbf{4}$ & 15 & 23 & 8 \\
\cline { 2 - 4 } $\mathbf{5}$ & 0 & 0 & 15 \\
\cline { 2 - 4 } Strongly Agree & 38 & 46 & 23 \\
\cline { 2 - 4 } & 23 & 15 & 23 \\
\cline { 2 - 4 } & & &
\end{tabular}

Table 7. (Group B) Overview of results for output quality factor

\begin{tabular}{|c|c|c|c|}
\hline \multirow{3}{*}{$\begin{array}{c}\text { Strongly Disagree } \\
2\end{array}$} & OUT $1(\%)$ & OUT $2(\%)$ & OUT $3(\%)$ \\
\hline & 0 & 0 & 8 \\
\hline & 8 & 8 & 8 \\
\hline 3 & 17 & 25 & 17 \\
\hline 4 & 8 & 17 & 25 \\
\hline 5 & 8 & 25 & 17 \\
\hline 6 & 42 & 17 & 17 \\
\hline Strongly Agree & 0 & 8 & 8 \\
\hline
\end{tabular}

Output Quality, Group A

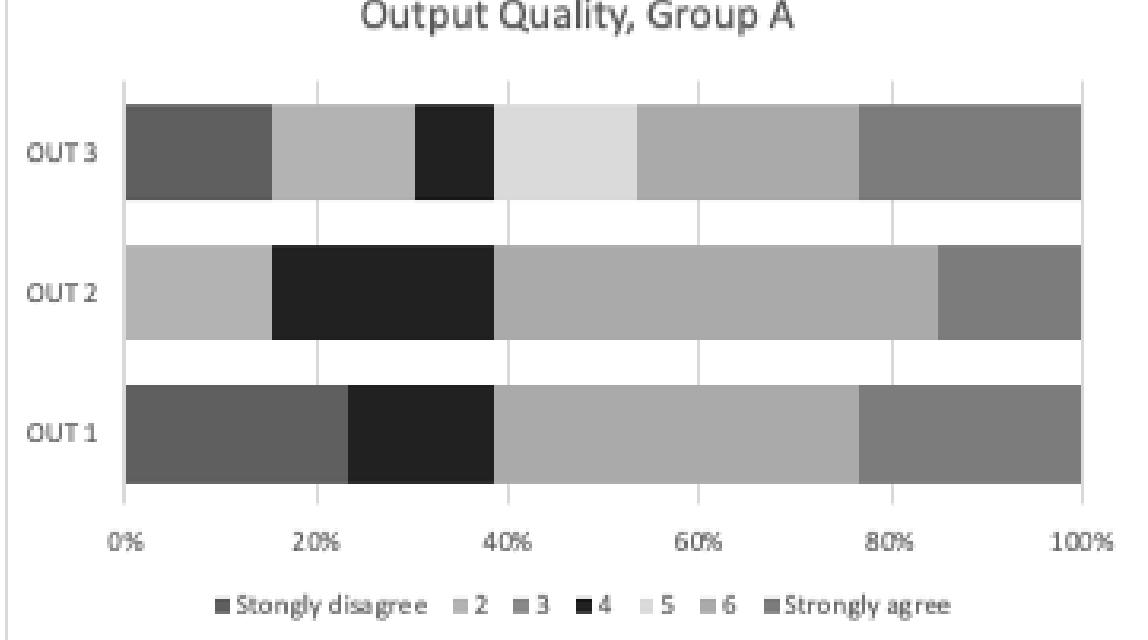

Figure 6. (Group A) Overview of results for output quality factor 


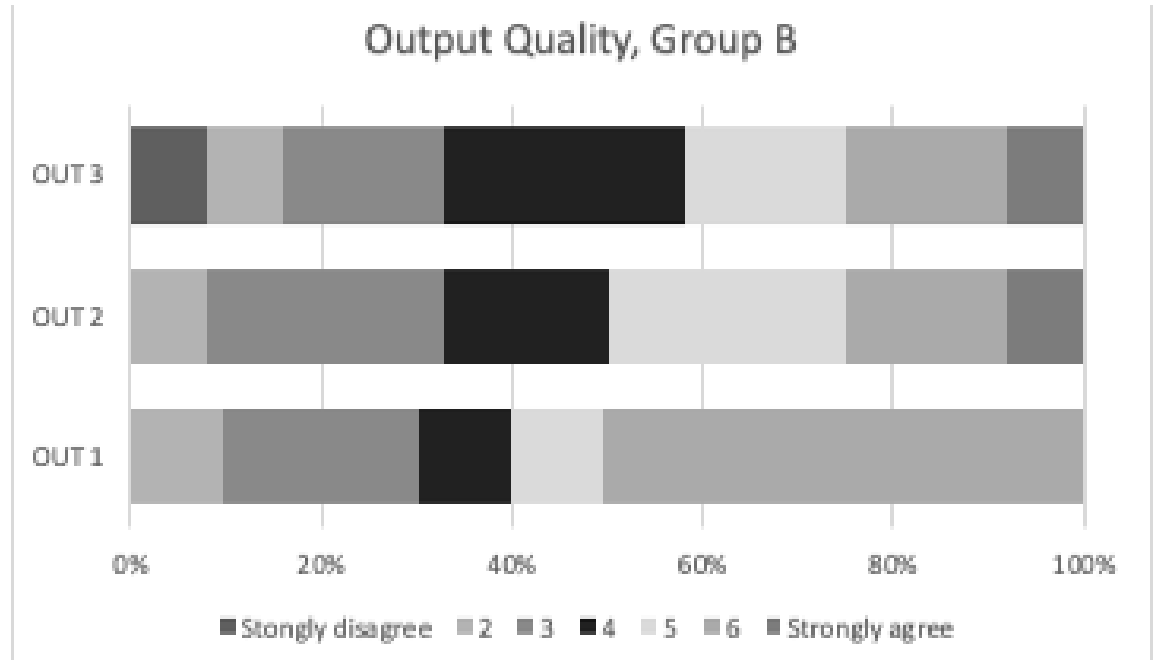

Figure 7. (Group B) Overview of results for output quality factor

\subsection{Statistical Tests}

A two-sample mean, t-test, assuming unequal variances, was run within all three TAM factors (PEOU, PU, OUT) and across all questions (Q1-Q4) to determine if there were significant effects between the groups.

For factor PEOU, $\mathrm{Q} 1(\mathrm{M}=4.85, \mathrm{SD}=1.95), \mathrm{Q} 2(\mathrm{M}=5.0, \mathrm{SD}=2.20), \mathrm{Q} 3(\mathrm{M}=4.85, \mathrm{SD}=$ $2.15)$, and $\mathrm{Q} 4(\mathrm{M}=4.85, \mathrm{SD}=2.0)$. This is illustrated in Figure 8.

Hence, there was no significant difference between Group A and Group B, Q1 (M = 5.17, SD = 1.60), $\mathrm{Q} 2(\mathrm{M}=4.50, \mathrm{SD}=1.62), \mathrm{Q} 3(\mathrm{M}=4.74, \mathrm{SD}=1.71)$, and $\mathrm{Q} 4(\mathrm{M}=5.16, \mathrm{SD}=1.64), \mathrm{t}(25)$ $=-0.03, \mathrm{p}=0.50$ across all PEOU factors $($ Table 1$)$.

The second factor, PU, for Group A, Q1 $(\mathrm{M}=4.38, \mathrm{SD}=2.14), \mathrm{Q} 2(\mathrm{M}=4.08, \mathrm{SD}=2.33), \mathrm{Q} 3$ $(\mathrm{M}=4.0, \mathrm{SD}=2.31), \mathrm{Q} 4(\mathrm{M}=4.70, \mathrm{SD}=2.06)$, revealed there was no significant difference between Group A and Group B, Q1 $(\mathrm{M}=4.45, \mathrm{SD}=1.31), \mathrm{Q} 2(\mathrm{M}=3.83, \mathrm{SD}=1.70), \mathrm{Q} 3(\mathrm{M}=$ 4.80, $\mathrm{SD}=1.64), \mathrm{Q} 4(\mathrm{M}=4.70, \mathrm{SD}=1.60), \mathrm{t}(25)=-0.57, \mathrm{p}=0.30$ across all PU factors(Table $1)$.

There was, however, a significant effect for the third factor, OUT. Group A, Q1 $(\mathrm{M}=4.80, \mathrm{SD}=$ $2.35), \mathrm{Q} 2=(\mathrm{M}=5.10, \mathrm{SD}=1.71), \mathrm{Q} 3(\mathrm{M}=4.51, \mathrm{SD}=2.30)$ showed a higher rating than Group $\mathrm{B}, \mathrm{Q} 1(\mathrm{M}=4.5, \mathrm{SD}=1.53), \mathrm{Q} 2(\mathrm{M}=4.42, \mathrm{SD}=1.51), \mathrm{Q} 3(\mathrm{M}=4.17, \mathrm{SD}=1.75), \mathrm{t}(25)=2.23$, $\mathrm{p}=0.05$, suggesting a higher preference for the non-responsive design. See Table 1 . 




Figure 8. Group A and B comparison

\section{DISCUSSION}

The first questions regarding Perceived Ease of Use (PEOU) were designed to determine the degree to which a person using the checkout experience would be free of effort. Analysis of PEOU, between responsive and non-responsive groups, revealed no significant difference, and did not support the hypotheses.

The next series of questions, Perceived Usefulness (PU), were designed to determine the degree to which a person using the checkout experience would enhance their performance. Analysis of $\mathrm{PU}$, between responsive and non-responsive groups, revealed no significant difference.

The last questions regarding Output Quality (OUT) were measuring the degree to which a person believes that using the checkout experience assists them in completing the task, i.e. finishing the checkout process. Analysis of OUT, between responsive and non-responsive groups, did show a significant difference. Indicating that the non-responsive design produced a more beneficial experience than the non-responsive one within the OUT category.

It was found that participants, overall, did rate the non-responsive design marginally higher within all three TAM categories. See Table 1. These results match those found by Holst (2013), who predicted that shoppers favor accessing e-commerce and m-commerce sites using their mobile phones [13].

However, these findings do not align with Cyr et al. (2006), and Duzevic (2016), who found that consumer loyalty is higher for $\mathrm{m}$-commerce sites that are responsive, aesthetically designed, and built from the user's perspective $[14,16]$.

Although responsive design is unarguably being a better fit for m-commerce and smartphone usage, the non-responsive design was rated by the experiment participants as a better experience. Previous research also posits that one reason for responsive design not being favored over nonresponsive design has to do with the mental model and its effects on PU. The results of this study align with the findings of Prezenski \& Russwinkel (2014), Nielsen (2010), Jung et al. (2015), who found that more experienced shoppers preferred a design that matched their mental model and beliefs about a system [19, 20, 21]. Anything that moved too far away from this mental model was rated lower regardless of the responsive design or any aesthetic enhancements. 
Computer Applications: An International Journal (CAIJ), Vol.8, No.1, February 2021

This further suggests that a user's mental model directly affects the intention to use a smartphone application. The OUT metrics also measures the degree to which a person believes a system helps them complete a task. Belief is hence also the foundation of the conceptual, mental model.

While the findings show that the non-responsive design was rated higher, there were some limitations to this study which may have affected the hypotheses not being supported. With a small sample size of 25 total participants, each condition that was tested had only 13 (Group A) and 12 (Group B). A larger sample size may have led to the current findings being able to uncover additional differences that may be present when measuring TAM on PU.

Also, while this study was completed on a randomized sample population, the individuals all work for TCGplayer and shop frequently on their marketplace. This unfortunately means that there was no way to remove any bias from their reactions and ratings while viewing either condition. Whether or not these limitations would have overridden the mental model assumed effect, is difficult to say and would need further investigation.

\section{Conclusions}

Based on these findings, it would be worth analyzing the differences between those who regularly shop on TCGplayer's marketplace against those who do not. Any future experimentation could also examine closely the relationship between the mental model and the new, responsive, shopping cart interface. Specifically, OUT responses could be examined to create a hypothesis connecting mental models and the importance of believing in a system's output.

This study did not ask questions specifically pertaining to the exact interface changes that were made when updating to the responsive shopping cart design. It could potentially be worth redesigning the experiment to capture sentiment around what features exactly caused friction byspecifically comparing the existing design with the features that were changed and how that aligned with mental model beliefs.

This study aimed to shed some light on the interconnected effects of responsive interface design on PEOU, PU, and OUT. As technology and web applications continue to grow it will always be important to yield to the user's mental model as a way of guiding the design and improving usability. While there is still more information to uncover, these findings help elucidate the effect of responsive and non-responsive designs on perceived usability.

\section{REFERENCES}

[1] Pahman, D. and Maupin, I. (2018). Markets, morality \& magic: the gathering: Insights from collectible card games for teaching free-market political economy. Presented at Association for Private Enterprise Education 2018 Annual Conference, Retrieved from: https://www.academia.edu/36369099/Markets_Morality_and_Magic_The_Gathering_Insights_from_ Collectible_Card_Games_for_Teaching_Free-Market_Political_Economy (Last Accessed 2/11/20).

[2] Stein, R. (2016). "65,000 and 1,000,000." Hipsters of the Coast. Retrieved from:https://www.hipstersofthecoast.com/2016/05/what-we-learned-65000/ (Last Accessed 2/11/20).

[3] Thomas, M. K., Shyjka, A., Kumm, S. andGjomemo, R. (2019). Educational Design Research for the Development of a Collectible Card Game for Cybersecurity Learning. Journal of Formative Design in Learning, 3(1), 27-38.

[4] Limbert, T. J. (2012). The Magic of community: Gathering of card players and subcultural expression (Doctoral dissertation, Bowling Green State University). 
Computer Applications: An International Journal (CAIJ), Vol.8, No.1, February 2021

[5] Marshall, B., Dreunen, J. and Wang. M. (2010). Trading card game industry. Super Data Research, New York, New York, Retrieved from: http://www.amarketplaceofideas.com/wpcontent/uploads/2015/12/TCG20101.pdf (Last Accessed 2/11/20).

[6] Paiva, F., Franco, A., Junior., G., Maia, J. (2018). Analyzing player profiles in collectable card games. SBgames. Retrieved from: http://www.sbgames.org/sbgames2018/files/papers/CulturaFull/188202.pdf (Last Accessed 2/11/20).

[7] Mahajan, A. (2019). The Dominance if the Online Marketplace in the retail industry. Entrepreneur. Retrieved from:https://www.entrepreneur.com/article/333614 (Last Accessed 2/11/20).

[8] Ali, F. (2018). Infographic: What are the top online marketplaces? Digital Commerce 360. Retrieved from: https://www.digitalcommerce360.com/article/infographic-top-online-marketplaces/(Last Accessed 2/11/20).

[9] Broom, G. (2019). Sick of eBay? Try the best alternative places to sell in 2019. Sale Hoo. Retrieved from: https://www.salehoo.com/blog/sick-of-ebay-try-these-alternative-places-to-sell (Last Accessed 2/11/20).

[10] Droesch, B. (2019). Amazon's marketplace is growing, but most of its sellers are active on eBay, too. Emarketer. Retrieved from: https://www.emarketer.com/content/amazon-s-marketplace-is-growingbut-most-of-its-sellers-are-active-on-ebay-too (Last Accessed 2/11/20).

[11] TCGplayer. (2019). What do the different price points on TCGplayer.com mean. Retrieved from: https://help.tcgplayer.com/hc/en-us/articles/222376867-Understanding-Prices-TCGplayer-com-Data (Last Accessed 2/11/20).

[12] Maff., A. (2018). Secondary Markets in E-commerce. Business. Retrieved from: https://blog.sellerschoice.digital/secondary-markets-e-commerce (Last Accessed 2/11/20).

[13] Fedorko, I., Bacik, R. \&Gavurova, B. (2018). Technology acceptance model in e-commerce segment. Management \& Marketing: Challenges for the Knowledge Society, (13), 1242-1256.

[14] Cyr, D., Head, M., Ivanov, A. (2006). Design aesthetics leading to m-loyalty in mobile commerce. Information \& Management, 43 (8), 950-963.

[15] Duchnicky, R., Kolers, P. (1983). Readability of text scrolled on visual display terminals as a function of window size. Human Factors, 25, 683-692.

[16] Duzevic, I., Delic, M. andKnezevic, B. (2016). Customer satisfaction and loyalty factors of mobile commerce among young retail customers in croatia. RevistaEletrônicaGestão\&Sociedade, v.10, n.27, p. $1459-1476$.

[17] Holst, C. (2013). How should your mobile and desktop sites differ? Retrieved from: https://baymard.com/blog/content-on-mobile-vs-desktop, (Last Accessed 2/11/20).

[18] Chan, S., Fang, X., Brezezinski, J., Zhou, Y., Xu, S., Lam, J. (2002). Usability for mobile commerce across multiple form factors. Journal of Electronic Commerce Research, 3(3).

[19] Nielsen, J. (2010). Mental Models. Nielsen Norman Group, Retrieved from: https://www.nngroup.com/articles/mental-models/ (Last Accessed 2/11/20).

[20] Jung, W., \&Yim, H. R. (2015). The Effects of Mental Model on Intention to Use Smartphone Applications. In Computer Science and its Applications. Springer, Berlin, Heidelberg, 217-222.

[21] Prezenski, S., \&Russwinkel, N. (2014). Combining cognitive ACT-R models with usability testing reveals user mental model while shopping with a smartphone application. International Journal on Advances in Intelligent Systems, (7) 700-716.

[22] Davis, F. (1989). Perceived usefulness, perceived ease of use, and user acceptance of information technology. MIS Quarterly, 13, 319-340.

[23] Lee, Y., Kozar, K. and Larsen, K (2003). The technology acceptance model: Past, present, and future. Communications of the Association for Information Systems, 12 (50).

[24] Goodhue, D. (1998). Development and Measurement Validity of a Task-Technology Fit Instrument for User Evaluations or Information Systems. Decision Sciences, 29(1), 105-138.

[25] Koufaris (2001). Applying the technology acceptance model and flow theory to online consumer behavior. Information Systems Research, 13, 205-223.

[26] Marangunic, N. and Granic, A. (2015). Technology acceptance model: A literature review from 1986 to 2013. Universal Access in the Information Society, 14(1), 81-95.

[27] Moore, C. and Benbasat, I. (1991). Development of an instrument to measure the perceptions of adopting an information technology innovation. Information Systems Research, 2, 192-222.

[28] Diop EB, Zhao S. and Duy, TV. (2019). An extension of the technology acceptance model for understanding travelers' adoption of variable message signs. PLoS ONE, 14(4). 
Computer Applications: An International Journal (CAIJ), Vol.8, No.1, February 2021

[29] Davis, F. (1986). A Technology Acceptance Model for empirically testing new end-user information systems: Theory and results. (Doctoral Dissertation, Sloan School of Management, Massachusetts Institute of Technology).

[30] Duda, S., Schiessl, J., Hess, M., Beier, M., Von Gizycki, T. (2002). Mobile usability: Guidelines for the development of user friendly mobile services. Usability Nutzerfreundliches Web-Design, 173199.

[31] Tarasewich, S., Strader, T., Mennecke, B. (2002). Wireless devices for mobile commerce: User interface design and mobility. Mobile Commerce: Technology, Theory, and Applications, 26-50.

[32] Tractinsky, N. (1997). Aesthetics and apparent usability: Empirically assessing cultural and methodological issues. Proceedings of the SIGCHI conference on Human Factors in Computing Systems, 115-122.

[33] Hu, Paul J., Patrick Y. K. Chau, Olivia R. Liu Sheng, Kar Yan Tam. (1999). Examining the technology acceptance model using physician acceptance of telemedicine technology. Journal of Management Information Systems, 16(2), 91-112.

[34] Greaux, C. (2015). Wizards of the Coast Bans a Magic Player and Sets Off a Tizzy Among Gamers. Observer. Retrieved from: http://observer.com/2015/07/wizards-of-the-coast(Last Accessed 2/11/20).

\section{AUTHORS}

Kimberly Fischer recently completed a masters degree in Human Computer Interaction from the State University of New York at Oswego. She now works as a User Experience (UX) Designer and Researcher at TCGplayer in Syracuse, New York.

Damian Schofield is a full professor and Director of the Human Computer Interaction masters program at the State University of New York at Oswego. 